\title{
INVESTIGATION OF NONUNIFORM ROD ELEMENTS STABILITY BY DIRECT INTEGRATION METHOD
}

\section{Yurii Krutii}

Scientific paper / Znanstveni rad

Odessa State Academy of Building and Architecture, Department of Information Technology and Applied Mathematics, $S c D$

Corresponding author: yurii.krutii@gmail.com

\begin{abstract}
The calculation for the equilibrium stability of a rod system with variable stiffness by the direct integration method is proposed. The method is based on the exact solutions of the corresponding differential equations. Using this method, the rod stability problem with arbitrary continuous variable flexural stiffness is solved. The formulas for the parameters of the frame structure stability are expressed in the analytical form and the method of their numerical implementation is provided. The frame structures with binomial distribution of stiffness are considered.
\end{abstract}

Keywords: rod stability; variable stiffness; coefficient of stability; critical forces; bent equilibrium forms

\section{ISTRAŽIVANJE STABILNOSTI ŠTAPNIH ELEMENATA PROMJENJIVE KRUTOSTI METODOM DIREKTNOG INTEGRIRANJA}

Sažetak: Predloženo je rješenje za jednadžbe stabilnosti štapnih sustava promjenjive krutosti metodom direktnog integriranja. Metoda se temelji na točnim rješenjima odgovarajućih diferencijalnih jednadžbi. Korištenjem ove metode riješen je problem stabilnosti štapa s promjenjivom krutosti na savijanje. Dane su formule za određivanje parametara stabilnosti štapnih konstrukcija u analitičkom obliku i dan je način njihove numeričke realizacije. Promatrana je štapna konstrukcija s binomnom raspodjelom krutosti.

Ključne riječi: stabilnost štapa; promjenjiva krutost; koeficijent stabilnosti; kritične sile; poremećaj stanja ravnoteže 


\section{INTRODUCTION}

Straight nonuniform rods are used as constructive elements or space structures. Examples of space structures include the columns of frame buildings, industrial high-rise structures (chimneys, water towers, or cooling towers), multipurpose steel supports used for power lines, wind generator supports, antennas of various structures, etc. The machine components, turbine blades, and parts of the bodies of rockets, ships, and bridges can be presented as constructive elements. The stability calculation of the listed rod elements is an actual scientific and practical problem.

According to the Euler concept, the critical force is determined from the differential equation that expresses the rod equilibrium in a deformation state. In the presence of the exact (analytical) solution of such an equation, the corresponding stability problem is solved comparatively simply. However, the objects listed above are typically characterized by variable stiffness, which requires the solutions of differential equations with variable coefficients.

It is clear that the exact solutions of these equations comprise qualitative information and form the complete picture of the physical phenomenon. However, an exact solution does not exist for most cases. This can be explained by the fact that the integration of the differential equation of the rod equilibrium is complicated when the rod stiffness is not constant [1, p. 331]. Consequently, the method of forth integration has gone to the background in stability theory. This article pertains to the development of the direct integration method, the use of which solves the problem of rod stability with arbitrary continuous variable bending stiffness.

\section{LITERATURE REVIEW}

Many scientific reports pertaining to the stability problems of nonuniform rod elements have been published. A large number of studies indicate the relevance and high practical importance of this problem. First, the previous works [2-28] are noteworthy, wherein, in the majority of the editions, various approximate methods have been used. However, certain functions of stiffness changes exist for which the exact solutions can be found. Recently, the variational iteration method, homotopy perturbation method [10-16], and discretization method [18] have been frequently used.

Considerable attention has been given to such cases in the publications [2,3]. Among the contemporary publications is the monograph [9], which contains a number of exact solutions for the stability problems of nonuniform rods. In general, for an arbitrary continuous stiffness as stated in the monographs [5, p. 23], [6, p. 82, 85], $[16, p .118]$, the corresponding equation of the rod stability cannot be integrated analytically.

In the work of the author [29], the exact solution for the differential equation of the rod stability with arbitrary continuous stiffness is obtained. It creates new perspectives for the further application of the direct integration method.

\section{INITIAL EQUATION AND PROBLEM STATEMENT}

The target of the research is a compressed straight rod under the action of axial influences. Additionally, it is considered that the rod is only loaded by the axial forces at the ends; therefore, the longitudinal force is constant everywhere along the rod. Figure 1 depicts the design model; Figure 2 shows the internal forces acting on the rod's element.

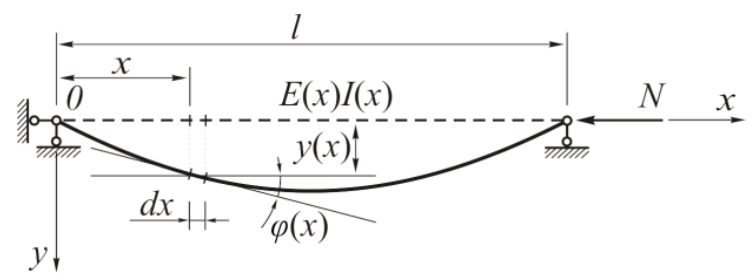

Figure 1 Design model of hinged rod

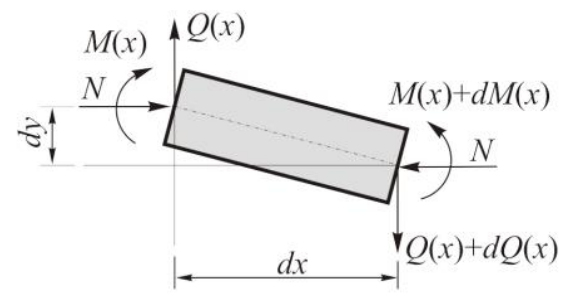

Figure 2 Internal forces acting upon the rod's element

Krutii, Y 
The symbols on Figures 1, 2 are $E(x) I(x)$ - variable flexural stiffness of a rod; $E(x)$ - modulus of elasticity; $I(x)$ - inertia moment of cross section; $N$ - constant axial load; $y(x)$ - the cross motion of the rod's axis point with coordinate $x ; \varphi(x)$ - the angular displacement; $M(x)$ - the bending moment; $Q(x)-$ the transverse force.

The relevant differential balance equation of the rod in the deformed state is correct for any boundary condition and has the form $[2,6,16]$ :

$$
\left(E(x) I(x) y^{\prime \prime}(x)\right)^{\prime \prime}+N y^{\prime \prime}(x)=0 .
$$

The statement of the problem is to define the critical forces for an arbitrary continuous variable stiffness based on the exact solution (1), for which the bent forms of the rod's equilibrium are possible and those forms are to be defined.

\section{PARAMETER DEFINITION OF ROD'S STATE}

The investigations presented herein are based on the author's previous work [29]. All the necessary formulas with the corresponding explanations are presented in the following.

Parameters $y(x), \varphi(x), M(x), Q(x)$, which characterize the stress-strain state of a rod will be expressed by the dimensionless fundamental solutions of equation (1). Therefore, the variable stiffness is shown in the form: $E(x) I(x)=E_{0} I_{0} A(x)$, where $E_{0} I_{0}$ - constant stiffness (the stiffness in the characteristic point of the rod), and $A(x)$ - dimensionless function, determines the stiffness function change along the rod.

The relevant formulas, expressed with the initial parameters $y(0), \varphi(0), M(0), Q(0)$, are of the forms [29]:

$$
\begin{gathered}
y(x)=y(0)+\varphi(0) l X_{2}(x)-M(0) \frac{l^{2}}{E_{0} I_{0} K}\left(1-X_{1}(x)\right)-Q(0) \frac{l^{3}}{E_{0} I_{0} K}\left(\frac{x}{l}-X_{2}(x)\right) ; \\
\varphi(x)=\varphi(0) \tilde{X}_{2}(x)+M(0) \frac{l}{E_{0} I_{0} K} \tilde{X}_{1}(x)-Q(0) \frac{l^{2}}{E_{0} I_{0} K}\left(1-\tilde{X}_{2}(x)\right) ; \\
M(x)=\varphi(0) \frac{E_{0} I_{0} K}{l} X_{2}(x)+M(0) X_{1}(x)+Q(0) l X_{2}(x) ; \\
Q(x)=Q(0),
\end{gathered}
$$

where $X_{n}(x)(n=1,2)$ - fundamental function of the equation (1), is determined by the series of absolute and uniform convergence:

$$
\begin{gathered}
X_{n}(x)=\alpha_{n, 0}(x)-K \alpha_{n, 1}(x)+K^{2} \alpha_{n, 2}(x)-K^{3} \alpha_{n, 3}(x)+\ldots, \\
K=N \frac{l^{2}}{E_{0} I_{0}} .
\end{gathered}
$$

According to the terminology accepted in [29], the functions $\alpha_{n, 0}(x)(n=1,2)$ are called the primary functions, and functions $\alpha_{n, k}(x)(n=1,2)(k=1,2,3 \ldots)$ are the generating functions. They are determined as follows:

$$
\begin{gathered}
\alpha_{n, 0}(x)=\left(\frac{x}{l}\right)^{n-1}, \alpha_{n, k}(x)=\frac{1}{l^{2}} \int_{0}^{x} \int_{0}^{x} \frac{1}{A(x)} \alpha_{n, k-1}(x) d x d x(k=1,2,3, \ldots) ; \\
\alpha_{n, k}(x)=\frac{1}{l^{2 k}} \int_{0}^{x} \int_{0}^{x} \frac{1}{A(x)} \ldots \int_{0}^{x} \int_{0}^{x} \frac{1}{A(x)} \int_{0}^{x} \int_{0}^{x} \frac{1}{A(x)} \alpha_{n, 0}(x) d x d x d x d x \ldots d x d x .
\end{gathered}
$$

Two formulas can be used for the generating functions - recurrence (8) and expanded (9). The multiplicity of the integrals in the formula (9) is $2 k$.

Functions $\tilde{X}_{n}(x)(n=1,2)$, which are present in formula (3) , are also determined absolutely and uniformly by a convergent series [29]:

\section{Krutii, Y}




$$
\tilde{X}_{n}(x)=\tilde{\alpha}_{n, 0}(x)-K \tilde{\alpha}_{n, 1}(x)+K^{2} \tilde{\alpha}_{n, 2}(x)-K^{3} \tilde{\alpha}_{n, 3}(x)+\ldots ;
$$

where

$$
\tilde{\alpha}_{n, 0}(x)=l \alpha_{n, 0}^{\prime}(x), \tilde{\alpha}_{n, k}(x)=l \alpha_{n, k}^{\prime}(x)(n=1,2)(k=1,2,3, \ldots) .
$$

As proven in [29], functions (8), (9), (11) are dimensionless. Investigating the dimension of right part of the formula (7), it is easy to establish that the parameter $K$ is also dimensionless. Therefore, the sums $X_{n}(x), \tilde{X}_{n}(x)(n=1,2)$ of the series (6), (10) will be dimensionless. Consequently, the dimension of the constant coefficients in the dimensionless functions in the right parts of formulas (2)-(5) is equal to the dimension of the corresponding left parts.

\section{ANALYTICAL REPRESENTATION FOR LONGITUDINAL FORCE}

According to (7), the general case of variable continuous stiffness is given as [29]

$$
N=K \frac{E_{0} I_{0}}{l^{2}}
$$

which in an analytical form that determines the dependence between the longitudinal force and other parameters of a mechanical system. As shown, the longitudinal force is directly proportional to the stiffness and inversely proportional to the square of the rod length. For certain cases of continuous variable stiffness such a formula is presented in monography [2]. Following the terminology accepted in [2], the dimensionless parameter $K$ will be called the stability coefficient. It will depend on the boundary condition and the function of stiffness change $A(x)$.

\section{REPRESENTATION OF GENERATING FUNCTIONS IN POWER SERIES FORM}

In the work [29], the calculation method for the generation functions was proposed. The method is based on the approximation of the integrand $f(x)=1 / A(x)$ by the polynomial. Herein, the integrand is represented by the Maclaurin series:

$$
f(x)=A_{0}+A_{1}\left(\frac{x}{l}\right)+A_{2}\left(\frac{x}{l}\right)^{2}+\ldots+A_{j}\left(\frac{x}{l}\right)^{j}+\ldots
$$

where

$$
A_{0}=\frac{1}{A(0)} \neq 0, A_{j}=\frac{l^{j} f^{(j)}(0)}{j !}(j=1,2,3, \ldots)
$$

is a dimensionless coefficient, and index $(j)$ signifies the order of the derivative. Owing to this approach, the integral of (9) can be calculated analytically. Consequently, the final calculation formulas will be exact.

Considering (13), direct from formula (9), each of the generating functions $\alpha_{n, k}(x)(n=1,2)(k=1,2,3, \ldots)$ will be presented by a power series. Further, considering that formula (9) contains only $2 k$ integrals, the power of the first summand of this series will be equal to $n+2 k-1$. Therefore, the generating functions $\alpha_{n, k}(x)$ can be represented in the form of

$$
\alpha_{n, k}(x)=\left(\frac{x}{l}\right)^{n+2 k-1} \sum_{j=0}^{\infty} d_{n, k, j}\left(\frac{x}{l}\right)^{j}
$$

where $d_{n, k, j}$ are the coefficients to be determined.

From formulas (8), (11), the ratios become

$$
\begin{gathered}
\tilde{\alpha}_{n, k}(x)=\frac{1}{l} \int_{0}^{x} f(x) \alpha_{n, k-1}(x) d x ; \\
\alpha_{n, k}(x)=\frac{1}{l} \int_{0}^{x} \tilde{\alpha}_{n, k}(x) d x .
\end{gathered}
$$

Krutii, Y 
According to (16), the product of the series $f(x)$ and $\alpha_{n, k-1}(x)$ is obtained and then the result is integrated. The product yields

$$
f(x) \alpha_{n, k-1}(x)=\left(\frac{x}{l}\right)^{2 k+n-3} \sum_{j=0}^{\infty} e_{n, k-1, j}\left(\frac{x}{l}\right)^{j} ; e_{n, k-1, j}=\sum_{i=0}^{j} A_{j-i} d_{n, k-1, i} .
$$

Therefore,

$$
\tilde{\alpha}_{n, k}(x)=\left(\frac{x}{l}\right)^{2 k+n-2} \sum_{j=0}^{\infty} \frac{e_{n, k-1, j}}{n+2 k+j-2}\left(\frac{x}{l}\right)^{j} .
$$

Based on (17), the following is obtained:

$$
\alpha_{n, k}(x)=\left(\frac{x}{l}\right)^{n+2 k-1} \sum_{j=0}^{\infty} \frac{e_{n, k-1, j}}{(n+2 k+j-2)(n+2 k+j-1)}\left(\frac{x}{l}\right)^{j} .
$$

Comparing the last formula with (15) yields

$$
d_{n, k, j}=\frac{e_{n, k-1, j}}{(n+2 k+j-2)(n+2 k+j-1)}(k=1,2,3, \ldots)(j=0,1,2 \ldots) .
$$

Eliminating the parameter $e_{n, k-1, j}$ yields

$$
d_{n, k, j}=\frac{\sum_{i=0}^{j} A_{j-i} d_{n, k-1, i}}{(n+2 k+j-2)(n+2 k+j-1)}(k=1,2,3, \ldots)(j=0,1,2, \ldots) .
$$

The predicted ratio is a recurrence according to the index $k$, which means that each following value $d_{n, k, j}$ is calculated using the previous one. Therefore, for the complete determination, it is necessary to use the initial values $d_{n, 0, j}(j=0,1,2, \ldots)$. Using (15) in the case when $k=0$ yields

$$
\alpha_{n, 0}(x)=\left(\frac{x}{l}\right)^{n-1} \sum_{j=0}^{\infty} d_{n, 0, j}\left(\frac{x}{l}\right)^{j}
$$

After comparing this expression with the first formula from (8), the following is obtained:

$$
d_{n, 0,0}=1 ; d_{n, 0, j}=0(j=1,2,3, \ldots) \text {. }
$$

Hence, formula (20) is completely determined; consequently, all the coefficients $d_{n, k, j}$ can be considered as known. It is noteworthy that these coefficients are dimensionless, because in their calculations only dimensionless values were used: $A_{j}(j=0,1,2, \ldots)$.

Formula (18), by considering (19), can be rewritten as

$$
\tilde{\alpha}_{n, k}(x)=\left(\frac{x}{l}\right)^{n+2 k-2} \sum_{j=0}^{\infty} \tilde{d}_{n, k, j}\left(\frac{x}{l}\right)^{j}
$$

where $\tilde{d}_{n, k, j}=(n+2 k+j-1) d_{n, k, j}$.

Thus, the generating functions $\alpha_{n, k}(x), \tilde{\alpha}_{n, k}(x)(n=1,2)(k=1,2,3, \ldots)$ are expressed by the corresponding power series (15) and (22).

\section{DETERMINATION OF CRITICAL FORCES AND FUNCTIONS OF BENT FORMS OF THE ROD EQUILIBRIUM}

The analytic form formulas for the state parameters and their numerical realization method allow the investigation of the rod stability with arbitrary continuous stiffness for any boundary condition. Herewith, owing to formula (12), the problem is limited to the determination of $K$ from the characteristic equations, which will be defined after the boundary conditions are realized. By determining the stability coefficients according to formula (12), the spectrum

\section{Krutii, Y}


of critical forces will be obtained; according to formula (2), the corresponding functions of the bent forms of the rod equilibrium will be determined.

The cantilever rod, which is widely used as a design model for building structures stability investigation, is discussed in the following (Figure 3).

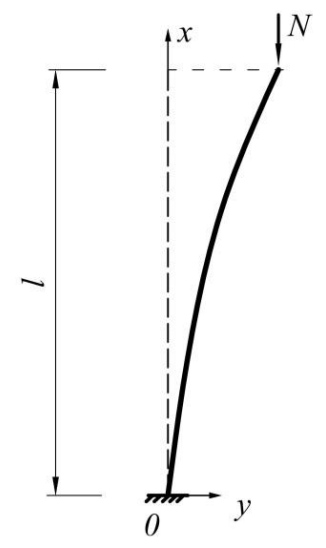

Figure 3 Design model of cantilever rod

The corresponding boundary conditions are written as

$$
y(0)=0 ; \varphi(0)=0 ; M(l)=0 ; Q(l)=0 .
$$

Therefore, $y(0), \varphi(0)$ are known in advance. Using (4), (5), and comparing the conditions at the end, i.e., $x=l$ with $M(0), Q(0)$ yields $M(0) X_{1}(l)=0 ; Q(0)=0$. It follows the characteristic equation $X_{1}(l)=0$, or

$$
\eta_{0}-\eta_{1} K+\eta_{2} K^{2}-\eta_{3} K^{3}+\ldots=0
$$

where $\eta_{k}=\alpha_{1, k}(l)(k=0,1,2, \ldots)$. The calculation of $\eta_{k}(k=0,1,2, \ldots)$ directly from (15), (21) yields

$$
\eta_{0}=1 ; \eta_{k}=\sum_{j=0}^{\infty} d_{1, k, j}(k=1,2,3, \ldots) .
$$

It is noteworthy that the left part of the characteristic equation (23) is an absolutely convergent series that stems from an absolute and uniform series convergence (6). Typically, to solve such an equation, the comparison method is used [30]. Using this method, the desired number of stability coefficients $K_{1}, K_{2}, K_{3}, \ldots$ with an arbitrary prespecified accuracy can be obtained. Having determined the roots of equation (23) in the increasing order, according to (12), the longitudinal force can be obtained:

$$
N_{j}=K_{j} \frac{E_{0} I_{0}}{l^{2}}(j=1,2,3, \ldots),
$$

where the bent forms of the rod equilibrium are possible.

For most bent forms, the following applies:

$$
y_{j}(x)=C_{j} Y_{j}\left(\frac{x}{l}\right)(j=1,2,3, \ldots),
$$

where $C_{j}$-constant dimensional multiplier; $Y_{j}\left(\frac{x}{l}\right)$ - dimensionless function, which will define the corresponding mode function of the rod equilibrium. In this case, (2) is presented in the form

$$
y(x)=-\frac{M(0) l^{2}}{E I_{0} K}\left(1-X_{1}(x)\right),
$$

subsequently

$$
Y_{j}\left(\frac{x}{l}\right)=\frac{1}{K_{j}}\left(1-X_{1}\left(x, K_{j}\right)\right)=\sum_{k=1}^{\infty}(-1)^{k-1} K_{j}^{k-1} \alpha_{1, k}(x) .
$$

\section{Krutii, Y}


Similarly, the characteristic equations and functions for the bent forms of the rod equilibrium can be written for any other boundary condition. It is noteworthy that for all six cases of homogeneous boundary conditions [1], the corresponding characteristic equations will be presented in the form of (23). However, the calculation formulas to determine $\eta_{k}(k=0,1,2, \ldots)$ will be different.

\subsection{Rods with binomial distribution of stiffness}

The set of homogenous rods with variable moment of inertia is analyzed; it changes according to the function:

$$
I(x)=I_{0}\left(1-(1-\delta) \frac{x}{l}\right)^{\alpha},
$$

where $I_{0}$ - moment of inertia of the rod cross-section at point $x=0 ; \alpha$-arbitrary real number; $\delta$ - constant, which satisfies the condition $0<\delta \leq 1$ because of homogeneity: $E(x) \equiv E=E_{0}=$ constant .

The investigation of the rod stability, of which the moment of inertia is provided by formula (26), some values of $\alpha$ and $\delta$ are presented in literature, i.e., in the monographs [2, 3, 9]. In most of such problems, the power index is considered as a natural number and more rarely as a negative integer. Herein, the solution can be obtained by the Bessel functions, except for cases $\alpha=2$ and $\alpha=4$, when it is represented by elementary functions. Solutions also exist when $\alpha$ is a fraction number [2]. Each of the listed cases requires individual investigations for a specific value of $\alpha$. The only (general) approach for any value of power index $\alpha$ has not been developed until recently.

Owing to the generality of the method proposed herein, for the investigation of rod stability with binomial stiffness distribution, the only algorithm for an arbitrary $\alpha$ is now obtained. To use this algorithm, it is sufficient to determine the coefficients of the series (13).

In this case,

$$
A(x)=\left(1-(1-\delta) \frac{x}{l}\right)^{\alpha}, f(x)=\left(1-(1-\delta) \frac{x}{l}\right)^{-\alpha} .
$$

Instead of using formula (14), it is more convenient to use the known binomial expansion with an arbitrary power index. Therefore,

$$
f(x)=1+\alpha(1-\delta)\left(\frac{x}{l}\right)+\frac{\alpha(\alpha+1)}{2 !}(1-\delta)^{2}\left(\frac{x}{l}\right)^{2}+\frac{\alpha(\alpha+1)(\alpha+2)}{3 !}(1-\delta)^{3}\left(\frac{x}{l}\right)^{3}+\ldots .
$$

As such, the coefficients of series (13) are determined by the following:

$$
A_{0}=1 ; A_{j}=\frac{\alpha(\alpha+1) \cdots(\alpha+j-1)}{j !}(1-\delta)^{j} \quad(j=1,2,3, \ldots) .
$$

In a particular case when $-\alpha=m$, where $m$ is a natural number, the binomial expansion (27) will be finite:

$$
f(x)=1-m(1-\delta)\left(\frac{x}{l}\right)+\frac{m(m-1)}{2 !}(1-\delta)^{2}\left(\frac{x}{l}\right)^{2}+\ldots+(-1)^{m}(1-\delta)^{m}\left(\frac{x}{l}\right)^{m} .
$$

In this case, all the coefficients among the binomial ones (28), except $A_{0}, A_{1}, \ldots, A_{m}$, will be zero.

The cantilever rods for the following values of power index are analyzed:

$$
\alpha=-4 ;-3 ;-2 ;-3 / 2 ;-1 ;-1 / 2 ; 1 / 2 ; 1 ; 3 / 2 ; 2 ; 3 ; 4 \text {. }
$$

The calculation data are shown in Tables $1-3$, where the first three stability coefficients are some possible values of parameter $\delta$. For all values of $\delta$, except the case when $\delta=1$, the coefficients $K_{1}, K_{2}, K_{3}$ were found as the roots of the characteristic equation (23) using numerical methods. For the case $\delta=1$, coefficients $K_{1}, K_{2}, K_{3}$ can be obtained in the analytical form. As shown from (26), $\delta=1$ means a uniform rod. In this case, the formulas (28), (20) are simplified:

$$
A_{0}=1 ; A_{j}=0(j=1,2,3, \ldots) ;
$$

Krutii, Y 
Investigation of nonuniform rod elements stability by direct integration method

$$
d_{n, k, j}=\frac{d_{n, k-1, j}}{(n+2 k+j-2)(n+2 k+j-1)}(k=1,2,3, \ldots)(j=0,1,2, \ldots) .
$$

Using the last formula and considering (21) yields:

$$
d_{n, k, 0}=\frac{1}{(n+2 k-1) !} ; d_{n, k, j}=0(k=1,2,3, \ldots)(j=1,2,3, \ldots) .
$$

Consequently, based on (24), (29), $\eta_{k}=1 /(2 k) !(k=1,2,3, \ldots)$. Subsequently, equation (23) will be written in the form $\cos \sqrt{K}=0$, where $K_{1}=(\pi / 2)^{2}, K_{2}=(3 \pi / 2)^{2}, K_{1}=(5 \pi / 2)^{2}$.

\begin{tabular}{|c|c|c|c|c|c|c|c|c|c|c|c|c|}
\hline \multirow{2}{*}{$\delta$} & \multicolumn{3}{|c|}{$\alpha=1$} & \multicolumn{3}{|c|}{$\alpha=2$} & \multicolumn{3}{|c|}{$\alpha=3$} & \multicolumn{3}{|c|}{$\alpha=4$} \\
\hline & $K_{1}$ & $K_{2}$ & $K_{3}$ & $K_{1}$ & $K_{2}$ & $K_{3}$ & $K_{1}$ & $K_{2}$ & $K_{3}$ & $K_{1}$ & $K_{2}$ & $K_{3}$ \\
\hline 0,01 & 1,4685 & 8,0326 & 20,2668 & 0,4995 & 1,4631 & 3,2996 & 0,0360 & 0,1214 & 0,2589 & 0,0010 & 0,0041 & 0,0173 \\
\hline 0,1 & 1,6211 & 10,3351 & 27,4677 & 0,8615 & 3,9327 & 9,9742 & 0,3208 & 1,2586 & 3,0581 & 0,0804 & 0,3269 & 0,7497 \\
\hline 0,2 & 1,7521 & 12,1663 & 32,8490 & 1,1095 & 6,0342 & 15,7947 & 0,5968 & 2,7441 & 6,8924 & 0,2643 & 1,1466 & 2,7575 \\
\hline 0,3 & 1,8653 & 13,7290 & 37,3762 & 1,3180 & 8,0289 & 21,3785 & 0,8533 & 4,4685 & 11,5713 & 0,4979 & 2,3765 & 5,9536 \\
\hline 0,4 & 1,9675 & 15,1422 & 41,4464 & 1,5067 & 9,9996 & 26,9304 & 1,0985 & 6,4138 & 16,9415 & 0,7566 & 4,0058 & 10,3387 \\
\hline 0,5 & 2,0621 & 16,4564 & 45,2198 & 1,6830 & 11,9749 & 32,5193 & 1,3364 & 8,5676 & 22,9534 & 1,0289 & 6,0348 & 15,9148 \\
\hline 0,6 & 2,1509 & 17,6984 & 48,7803 & 1,8505 & 13,9674 & 38,1753 & $\begin{array}{l}1,5691 \\
\end{array}$ & 10,9209 & 29,5726 & 1,3093 & 8,4647 & 22,6829 \\
\hline 0,7 & 2,2351 & 18,8850 & 52,1786 & 2,0115 & 15,9838 & 43,9137 & 1,7977 & 13,4666 & 36,7735 & 1,5947 & 11,2962 & 30,6438 \\
\hline 0,8 & 2,3155 & 20,0270 & 55,4477 & 2,1674 & 18,0279 & 49,7422 & 2,0233 & 16,1991 & 44,5362 & 1,8835 & 14,5302 & 39,7976 \\
\hline 0,9 & 2,3928 & 21,1323 & 58,6108 & 2,3191 & 20,1017 & 55,6653 & 2,2464 & 19,1137 & 52,8445 & 2,1746 & 18,1669 & 50,1447 \\
\hline 1 & $\left(\frac{\pi}{2}\right)^{2}$ & $\left(\frac{3 \pi}{2}\right)^{2}$ & $\left(\frac{5 \pi}{2}\right)^{2}$ & $\left(\frac{\pi}{2}\right)^{2}$ & $\left(\frac{3 \pi}{2}\right)^{2}$ & $\left(\frac{5 \pi}{2}\right)^{2}$ & $\left(\frac{\pi}{2}\right)^{2}$ & $\left(\frac{3 \pi}{2}\right)^{2}$ & $\left(\frac{5 \pi}{2}\right)^{2}$ & $\left(\frac{\pi}{2}\right)^{2}$ & $\left(\frac{3 \pi}{2}\right)^{2}$ & $\left(\frac{5 \pi}{2}\right)^{2}$ \\
\hline
\end{tabular}

Table 1 Stability coefficients for natural values of power index

Table 2 Stability coefficients for negative integer values of power index

\begin{tabular}{c|ccc|ccc|ccc|ccc}
\hline \multirow{2}{*}{$\delta$} & \multicolumn{3}{|c|}{$\alpha=-1$} & \multicolumn{3}{c|}{$\alpha=-2$} & \multicolumn{3}{c|}{$\alpha=-3$} & \multicolumn{3}{c}{$\alpha=-4$} \\
\cline { 2 - 13 } & $K_{1}$ & $K_{2}$ & $K_{3}$ & $K_{1}$ & $K_{2}$ & $K_{3}$ & $K_{1}$ & $K_{2}$ & $K_{3}$ & $K_{1}$ & $K_{2}$ & $K_{3}$ \\
\hline 0,01 & 3,4629 & 43,7063 & 127,7803 & 4,4563 & 72,4336 & 218,1364 & 5,4487 & 108,368 & 332,6611 & 6,4403 & 151,5018 & 619,5938 \\
0,1 & 3,3438 & 40,1408 & 115,8435 & 4,2316 & 64,1656 & 190,4871 & 5,1245 & 94,2259 & 285,4499 & 6,0199 & 130,2837 & 354,1293 \\
0,2 & 3,2197 & 36,7773 & 105,0114 & 3,9911 & 56,1031 & 164,1179 & 4,7728 & 80,2221 & 239,3418 & 5,5603 & 109,1183 & 330,7097 \\
0,3 & 3,1037 & 33,9281 & 96,1421 & 3,7612 & 49,1571 & 141,9975 & 4,4317 & 68,0082 & 199,8996 & 5,1106 & 90,5162 & 270,0892 \\
0,4 & 2,9951 & 31,4950 & 88,7628 & 3,5423 & 43,2225 & 123,5906 & 4,1031 & 57,5218 & 166,8084 & 4,6735 & 74,4635 & 218,7992 \\
0,5 & 2,8932 & 29,3992 & 82,5275 & 3,3349 & 38,1761 & 108,2998 & 3,7888 & 48,6441 & 139,4615 & 4,2519 & 60,8771 & 176,3629 \\
0,6 & 2,7976 & 27,5786 & 77,1846 & 3,1391 & 33,8916 & 95,5609 & 3,4900 & 41,2116 & 117,0723 & 3,8487 & 49,5920 & 141,9446 \\
0,7 & 2,7076 & 25,9840 & 72,5499 & 2,9547 & 30,2505 & 84,8886 & 3,2079 & 35,0365 & 98,8122 & 3,4665 & 40,3699 & 114,4262 \\
0,8 & 2,6228 & 24,5767 & 68,4868 & 2,7815 & 27,1471 & 75,8855 & 2,9432 & 29,9273 & 83,9135 & 3,1078 & 32,9262 & 92,6024 \\
0,9 & 2,5429 & 23,3258 & 64,8916 & 2,6192 & 24,4911 & 68,2345 & 2,6964 & 25,7037 & 71,7175 & 2,7743 & 26,9648 & 75,3445 \\
1 & $\left(\frac{\pi}{2}\right)^{2}$ & $\left(\frac{3 \pi}{2}\right)^{2}$ & $\left(\frac{5 \pi}{2}\right)^{2}$ & $\left(\frac{\pi}{2}\right)^{2}$ & $\left(\frac{3 \pi}{2}\right)^{2}$ & $\left(\frac{5 \pi}{2}\right)^{2}$ & $\left(\frac{\pi}{2}\right)^{2}$ & $\left(\frac{3 \pi}{2}\right)^{2}$ & $\left(\frac{5 \pi}{2}\right)^{2}$ & $\left(\frac{\pi}{2}\right)^{2}$ & $\left(\frac{3 \pi}{2}\right)^{2}$ & $\left(\frac{5 \pi}{2}\right)^{2}$ \\
\hline
\end{tabular}

Krutii, Y 
Table 3 Stability coefficients for fractional values of power index

\begin{tabular}{|c|c|c|c|c|c|c|c|c|c|c|c|c|}
\hline \multirow{2}{*}{$\delta$} & \multicolumn{3}{|c|}{$\alpha=-3 / 2$} & \multicolumn{3}{|c|}{$\alpha=-1 / 2$} & \multicolumn{3}{|c|}{$\alpha=1 / 2$} & \multicolumn{3}{|c|}{$\alpha=3 / 2$} \\
\hline & $K_{1}$ & $K_{2}$ & $K_{3}$ & $K_{1}$ & $K_{2}$ & $K_{3}$ & $K_{1}$ & $K_{2}$ & $K_{3}$ & $K_{1}$ & $K_{2}$ & $K_{3}$ \\
\hline 0,01 & 3,9598 & 57,1684 & 169,9344 & 2,9655 & 32,0503 & 91,6876 & 1,9684 & 14,1894 & 37,8368 & 0,9706 & 3,7973 & 8,9962 \\
\hline 0,1 & 3,7868 & 51,3955 & 150,6123 & 2,9035 & 30,4093 & 86,2033 & 2,0383 & 15,5272 & 42,1958 & 1,2240 & 6,5325 & 16,9797 \\
\hline 0,2 & 3,6037 & 45,8411 & 132,5571 & 2,8404 & 28,9049 & 81,4256 & 2,1034 & 16,6474 & 45,5916 & 1,4186 & 8,6703 & 23,0679 \\
\hline 0,3 & 3,4304 & 41,0944 & 117,5922 & 2,7823 & 27,6410 & 77,5514 & 2,1610 & 17,5865 & 48,3655 & 1,5832 & 10,5688 & 28,4693 \\
\hline 0,4 & 3,2667 & 37,0438 & 105,1614 & 2,7284 & 26,5572 & 74,3061 & 2,2134 & 18,4134 & 50,7771 & 1,7314 & 12,3525 & 33,5476 \\
\hline 0,5 & 3,1123 & 33,5821 & 94,7662 & 2,6781 & 25,6129 & 71,5227 & 2,2618 & 19,1614 & 52,9426 & 1,8689 & 14,0688 & 38,4384 \\
\hline 0,6 & 2,9670 & 30,6131 & 85,9963 & 2,6309 & 24,7795 & 69,0924 & 2,3073 & 19,8498 & 54,9266 & 1,9985 & 15,7415 & 43,2090 \\
\hline 0,7 & 2,8303 & 28,0541 & 78,5280 & 2,5866 & 24,0362 & 66,9404 & 2,3502 & 20,4910 & 56,7693 & 2,1221 & 17,3841 & 47,8983 \\
\hline 0,8 & 2,7018 & 25,8363 & 72,1095 & 2,5447 & 23,3672 & 65,0133 & 2,3910 & 21,0936 & 58,4978 & 2,2410 & 19,0055 & 52,5305 \\
\hline 0,9 & 2,5809 & 23,9026 & 66,5458 & 2,5050 & 22,7605 & 63,2715 & 2,4300 & 21,6639 & 60,1316 & 2,3558 & 20,6116 & 57,1222 \\
\hline 1 & $\left(\frac{\pi}{2}\right)^{2}$ & $\left(\frac{3 \pi}{2}\right)^{2}$ & $\left(\frac{5 \pi}{2}\right)^{2}$ & $\left(\frac{\pi}{2}\right)^{2}$ & $\left(\frac{3 \pi}{2}\right)^{2}$ & $\left(\frac{5 \pi}{2}\right)^{2}$ & $\left(\frac{\pi}{2}\right)^{2}$ & $\left(\frac{3 \pi}{2}\right)^{2}$ & $\left(\frac{5 \pi}{2}\right)^{2}$ & $\left(\frac{\pi}{2}\right)^{2}$ & $\left(\frac{3 \pi}{2}\right)^{2}$ & $\left(\frac{5 \pi}{2}\right)^{2}$ \\
\hline
\end{tabular}

As an example, the function graphs of the bent forms of the rod equilibrium for cases $\alpha=2, \delta=0,3$ are presented in Figure 4.
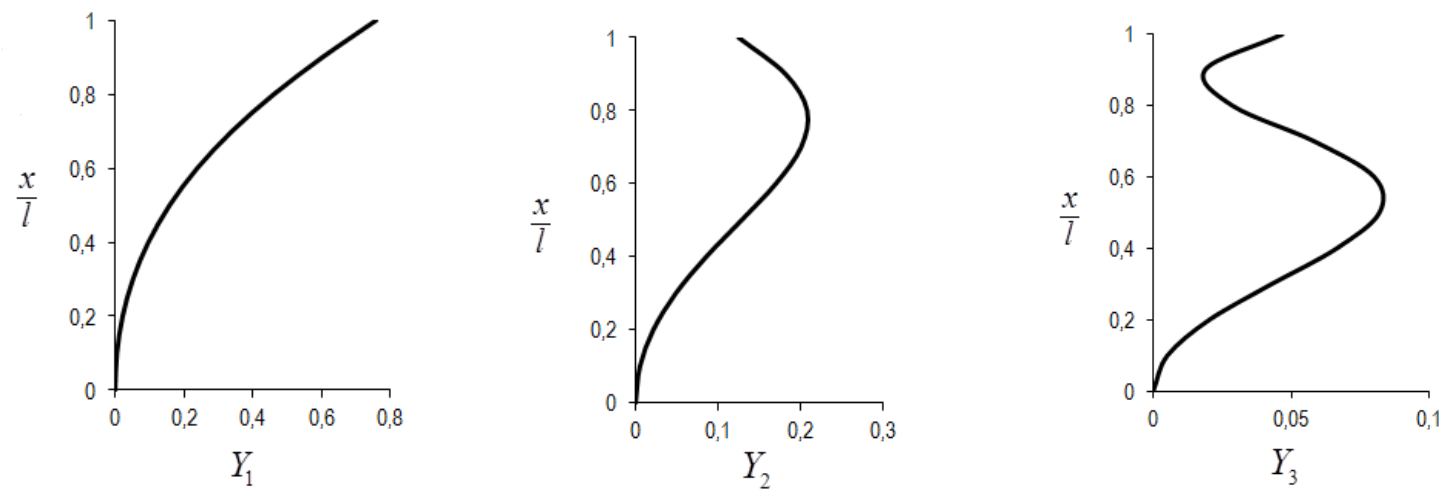

Figure 4 Graphs of functions of the bent forms of rod equilibrium

To confirm validate the author's method and confirm its accuracy, Table 4 contains the comparison of the data from Table 1 with the corresponding data contained in the monograph $[9, p .57]$, where the first coefficients of the oscillation for the power index $\alpha=1 ; 2 ; 3 ; 4$ are calculated. As shown, the results are equal.

Table 4 Comparison of the first coefficients of stability $K_{1}$

\begin{tabular}{c|cc|cc|cc|cc}
\hline \multirow{2}{*}{$\delta$} & \multicolumn{2}{|c|}{$\alpha=1$} & \multicolumn{2}{c|}{$\alpha=2$} & \multicolumn{2}{c|}{$\alpha=3$} & \multicolumn{2}{c}{$\alpha=4$} \\
\cline { 2 - 9 } & $\begin{array}{c}\text { Author's } \\
\text { method }\end{array}$ & {$[9]$} & $\begin{array}{c}\text { Author's } \\
\text { method }\end{array}$ & {$[9]$} & $\begin{array}{c}\text { Author's } \\
\text { method }\end{array}$ & {$[9]$} & $\begin{array}{c}\text { Author's } \\
\text { method }\end{array}$ & {$[9]$} \\
\hline 0,1 & 1,6211 & 1,621 & 0,8615 & 0,862 & 0,3208 & 0,321 & 0,0804 & 0,080 \\
0,3 & 1,8653 & 1,865 & 1,3180 & 1,318 & 0,8533 & 0,853 & 0,4979 & 0,498 \\
0,5 & 2,0621 & 2,062 & 1,6830 & 1,683 & 1,3364 & 1,336 & 1,0289 & 1,029 \\
0,7 & 2,2351 & 2,235 & 2,0115 & 2,012 & 1,7977 & 1,798 & 1,5947 & 1,595 \\
0,9 & 2,3928 & 2,393 & 2,3191 & 2,319 & 2,2464 & 2,246 & 2,1746 & 2,175 \\
\hline
\end{tabular}

Considering the stability coefficient $K$ as a function of variable $\delta$, and the values of these functions that correspond to the values of independent variable $0<\delta \leq 1$, the function $K$ is approximated by a polynomial. Consequently, for each of the cases above, the formulas can be written in the analytical form for the first three critical forces. Herein, only the formulas for some of these forces are presented because they reflect the practical building structure design. Using notations $N_{1}=N_{c r}, K_{1}=K_{c r}$, and according to (25), the following is obtained:

Krutii, Y 


$$
N_{c r}=K_{c r} \frac{E I_{0}}{l^{2}} .
$$

Moreover, the coefficients $K_{c r}=K_{c r}(\delta)$ are determined by the formulas are presented in Table 5 .

Table 5 Formulas for the first coefficients of stability

\begin{tabular}{rc}
\hline$\alpha$ & $K_{c r}(\delta)$ \\
\hline 1 & $1,4523+1,8249 \delta-1,9545 \delta^{2}+1,8207 \delta^{3}-0,6770 \delta^{4}$ \\
2 & $0,4471+5,4767 \delta-17,5811 \delta^{2}+45,5884 \delta^{3}-65,0592 \delta^{4}+47,1309 \delta^{5}-13,5358 \delta^{6}$ \\
3 & $0,0123+3,1073 \delta-1,1514 \delta^{2}+0,5033 \delta^{3}$ \\
4 & $3,4728-1,3162 \delta+0,3137 \delta^{2}$ \\
-1 & $4,4828-2,5743 \delta+0,5591 \delta^{2}$ \\
-2 & $5,4940-3,7856 \delta+0,7531 \delta^{2}$ \\
-3 & $6,4876-4,7087 \delta+0,2637 \delta^{2}+0,4254 \delta^{3}$ \\
-4 & $3,9776-1,9519 \delta+0,4439 \delta^{2}$ \\
$-3 / 2$ & $2,9722-0,7106 \delta+0,2814 \delta^{2}-0,0760 \delta^{3}$ \\
$-1 / 2$ & $1,9606+0,8320 \delta-0,6919 \delta^{2}+0,5636 \delta^{3}-0,1971 \delta^{4}$ \\
$1 / 2$ & $0,9391+3,3628 \delta-6,6145 \delta^{2}+11,1945 \delta^{3}-9,5711 \delta^{4}+3,1574 \delta^{5}$ \\
$3 / 2$ &
\end{tabular}

Each time, the degree of the approximating polynomial was chosen upon the condition that the coefficient of determination was not less than 0.9999 .

\subsection{Rod elements in the form of truncated cone with solid and tubular cross sections}

As an example, two tapered rods are examined. The first rod is a truncated cone with a solid cross section (Figure 5). The second one is a truncated cone with a tubular cross section and variable wall thickness (Figure 6).

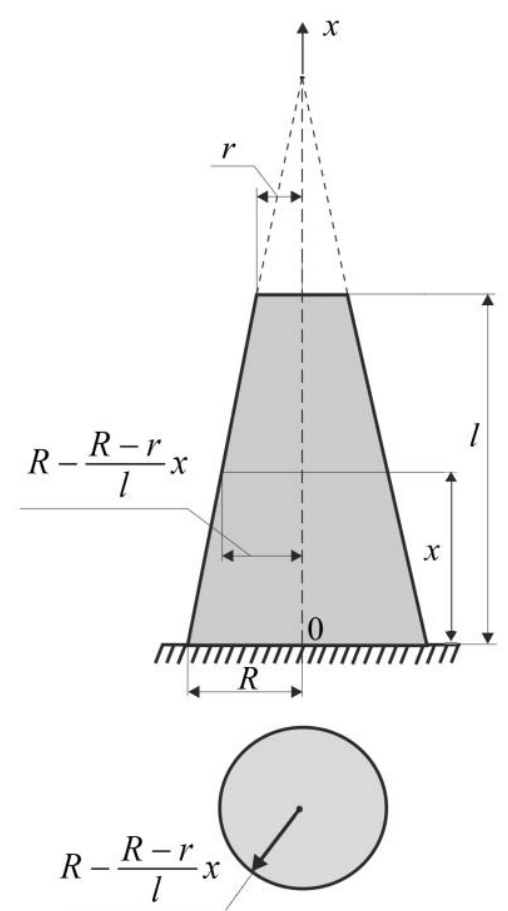

Figure 5 Truncated cone with solid cross section

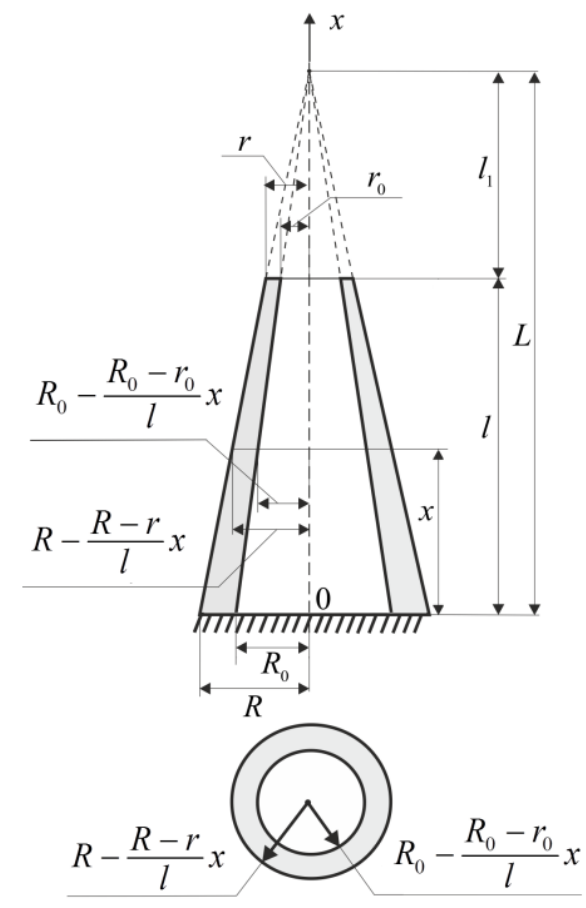

Figure 6 Truncated cone with tubular cross section

\section{Krutii, Y}


For the solid cone and tubular cone, the following hold, respectively:

$$
\begin{gathered}
I(x)=\frac{\pi R^{4}}{4}\left(1-\left(1-\frac{r}{R}\right) \frac{x}{l}\right)^{4} ; \\
I(x)=\frac{\pi}{4}\left(R^{4}\left(1-\left(1-\frac{r}{R}\right) \frac{x}{l}\right)^{4}-R_{0}^{4}\left(1-\left(1-\frac{r_{0}}{R_{0}}\right) \frac{x}{l}\right)^{4}\right) .
\end{gathered}
$$

Formula (32) can be simplified using the equality: $r / R=r_{0} / R_{0}=l_{1} / L$, which stems from the similarity of the rectangular triangle in Figure 6. Consequently,

$$
I(x)=\frac{\pi\left(R^{4}-R_{0}^{4}\right)}{4}\left(1-\left(1-\frac{r}{R}\right) \frac{x}{l}\right)^{4} .
$$

Each of the formulas (31), (33) is the particular case of (26); moreover, for a solid rod $I_{0}=\pi R^{4} / 4$, and for the rod with a tubular cross section $I_{0}=\pi\left(R^{4}-R_{0}^{4}\right) / 4$. In both cases, $\alpha=4, \delta=r / R \leq 1$, and both rods will have the same stability coefficients, as presented in Table 1 for the corresponding values of $\delta$.

For any value of $\delta$ in the interval $0,01 \leq \delta \leq 1$, formula (30) for both rods will have the form:

$$
N_{c r}=\left(-0,0087+0,4911 \delta+5,3737 \delta^{2}-5,4167 \delta^{3}+2,0307 \delta^{4}\right) \frac{E I_{0}}{l^{2}} .
$$

\section{RESULTS AND DISCUSSION}

The direct integration method is developed in this research. The necessary formulas for the investigation of the straight rod stability with arbitrary continuous variable bending stiffness are provided in the analytical form. The primary results are as follows:

1. The numerical implementation method of the previously obtained solutions for arbitrary boundary conditions on the ends of the considered rods is proposed;

2. The procedure for obtaining the critical forces and functions of the bent forms of the rod equilibrium (by the cantilever rod example) is determined;

3. A general stability investigation algorithm for a set of rods with a binomial distribution of stiffness is formulated. The first three coefficients of stability are calculated and the corresponding bent forms of equilibrium are determined. The analytical formulas for the stability coefficients are obtained;

4. The first critical force for a truncated cone with solid and tubular cross sections is determined in the analytical form.

In particular, the results obtained by the proposed method agree with the previously known data, which are interpreted in the scientific literature as exact. This indicates the high accuracy of the method. Further, the proposed approach allows the finite engineering formulas to be obtained for the direct calculation of critical forces (e.g., (32)) for any rod with variable continuous stiffness.

According to the author's opinion, this analytical method eliminates the necessity of further using any approximate method for this class of problems.

\section{References}

[1] Perelmuter, A. V.; Slivker, V. I. 2007: Ustoychivost ravnovesiya constructsiy i rodstvennye problemy, Toм 1, SCAD SOFT, Moscow. (in Russian)

[2] Dinnik, A. N. 1935: Ustoychivost uprugikh sistem, ONTI, Moscow. (in Russian)

[3] Papkovich, P. F. 1963: Trudy po stroitelnoy mekhanike korablya, V. 4, Gosudarstvennoye soyuznoye izdatelstvo sudostroitelnoy promyshlennosti, Leningrad. (in Russian)

[4] Timoshenko, S. P.; Gere, J. M. 1961: Theory of Elastic Stability, McGraw-Hill, New York.

Krutii, Y 
[5] Birger, I. A.; Panovko, Ya. H. 1968: Prochnost, ustoychivost, kolebaniya: spravochnik v 3 tomakh, Vol. 3 , Mashinostroyeniye, Moscow. (in Russian)

[6] Alphutov, N. A. 1978: Osnovy rascheta na ustoychivost uprugikh sistem, Mashinostroyeniye, Moscow. (in Russian)

[7] Almroth, B. O.; Brush, D. O. 1975: Buckling of bars, plates and shells. Mc Graw-Hill, New York.

[8] Bazant, Z. P.; Cedolin, L. 1991: Stability of Structures, Oxford University Press, New York.

[9] Wang, C. M.; Wang, C. Y; Reddy, J. N. 2005: Exact solutions for buckling of structural members, CRC Press LLC, Florida.

[10] Atay, M. T. 2009: Determination of critical buckling loads for variable stiffness Euler columns using homotopy perturbation method. International Journal of Nonlinear Sciences and Numerical Simulation, 10 (2), pp. 199-206. DOl: 10.1515/IJNSNS.2009.10.2.199

[11] Atay, M. T.; Coşkun, S. B. 2009: Elastic stability of Euler columns with a continuous elastic restraint using variational iteration method. Computers \& Mathematics with Applications, 58 (11-12), pp. 2528-2534. https://doi.org/10.1016/j.camwa.2009.03.051

[12] Atay, M. T. 2010: Determination of buckling loads of tilted buckled column with varying flexural rigidity using variational iteration method. International Journal of Nonlinear Sciences and Numerical Simulation, 11 (2), pp. 97-104. https://doi.org/10.1515/IJNSNS.2010.11.2.97

[13] Coşkun, S. B. 2009: Determination of critical buckling loads for Euler columns of variable flexural stiffness with a continuous elastic restraint using homotopy perturbation method. International Journal of Nonlinear Sciences and Numerical Simulation, 10 (2), pp. 191-198. DOI: 10.1515//JNSNS.2009.10.2.191

[14] Coşkun, S. B.; Atay, M. T. 2009: Determination of critical buckling load for elastic columns of constant and variable cross-sections using variational iteration method. Computers \& Mathematics with Applications, 58 (11-12), pp. 2260-2266. https://doi.org/10.1016/j.camwa.2009.03.072

[15] Coşkun, S. B. 2010: Analysis of Tilt-Buckling of Euler Columns with Varying Flexural Stiffness Using Homotopy Perturbation Method. Mathematical Modelling and Analysis, 15 (3), pp. 275-286, DOI: 10.3846/1392-6292.2010.15.275-286

[16] Coşkun, S. B. 2012: Advances in computational stability analysis, InTech, Rijeka

[17] Huang, Y.; Luo, Q. Z. 2011: A simple method to determine the critical buckling loads for axially inhomogeneous beams with elastic restraint. Computers \& Mathematics with Applications, 61(9), pp. 25102517. https://doi.org/10.1016/j.camwa.2011.02.037

[18] Tatsiy, R. M.; Ushak, T. I. 2009: Metod dyskretyzatsii v zadachakh stiykosti stryzhnevykh system zminnoyi zhorstkosti. Visnyk natsionalnoho universytetu «Lvivska politekhnika», 643, pp. 57-63. (in Ukrainian)

[19] Arbabi, F., Li, F. 1991: Buckling of variable cross-section columns-integral equation approach. Journal of Structural Engineering, 117(8), pp. 2426-2441. https://doi.org/10.1080/15397734.2017.1292142

[20] Eisenberger, M. 1991: Buckling loads for variable cross-section members with variable axial forces. International Journal of Solids and Structures, 27(2), pp. 135-143. https://doi.org/10.1016/00207683(91)90224-4

[21] Elishakoff, I., Pellegrini, F. 1987: Application of Bessel and Lommel functions and the undetermined multiplier Galerkin method version for instability of non-uniform column. Journal of Sound and Vibration, 115(1), pp. 182-186.

[22] Elishakoff, I., Pellegrini, F. 1988: Exact solutions for buckling of some divergence-type non-conservative systems in terms of Bessel and Lommel functions. Computer methods in applied mechanics and engineering, 66(1), pp. 107-119.

[23] Gere, J. M., Carter, W. O. 1962: Critical buckling loads for tapered columns. Journal of the Structural Division, 88(1), pp. 1-12.

[24] Li, Q., Cao, H., Li, G. 1994: Stability analysis of a bar with multi-segments of varying cross-section. Computers and structures, 53(5), p. 1085-1089. https://doi.org/10.1016/0045-7949(94)90154-6

[25] Quusheng, L., Hong, C., Guiqing, L. 1995: Stability analysis of bars with varying cross-section. International Journal of Solids and Structures, 32(21), pp. 3217-3228. https://doi.org/10.1016/0020-7683(94)00272-X 
[26] Sampaio, Jr. J. H., Hundhausen, J. R. 1998: A mathematical model and analytical solution for buckling of inclined beam columns. Applied Mathematical Modelling, 22(6), pp. 405-421. https://doi.org/10.1016/S0307904X(98)10014-8

[27] Siginer, A. 1992: Buckling of columns of variable flexural rigidity. Journal of engineering mechanics, 118(3), pp. 640-643. DOI: 10.1061/(ASCE)0733-9399(1992)118:3(640)

[28] Okay, F., Atay, M. T., Coçkun, S. B. 2010: Determination of buckling loads and mode shapes of a heavy vertical column under its own weight using the variational iteration method. International Journal of Nonlinear Sciences and Numerical Simulation, 11(10), pp. 851-857. DOI: 10.1515/IJNSNS.2010.11.10.851

[29] Krutiy, Yu. S. 2016: Development of problem-solving technique of deformable systems' stability and vibrations with variable continuous parameters. Thesis for Doctor Degree in Technical Sciences, Odessa, http://lutsk-ntu.com.ua/sites/default/files/disertaciya krutiy yu.s.pdf

[30] Illin, V. P.; Karpov, V. P.; Maslennikova, A. M. 1990: Chislennyie metody resheniya zadach stroitel'noi mekhaniki, Vysheishaia shkola, Minsk.

Please cite this article as:

Krutii, Y: Investigation of nonuniform rod elements stability by direct integration method, Electronic Journal of the Faculty of Civil Engineering Osijek-e-GFOS, 16, pp. 24-36, https://doi.org/10.13167/2018.16.3 